Erich Frauwallner

Die Philosophie des Buddhismus 



\title{
Erich Frauwallner
}

\section{DIE PHILOSOPHIE DES BUDDHISMUS}

\author{
Fünfte Auflage
}

Mit einem Vorwort von

Eli Franco und Karin Preisendanz

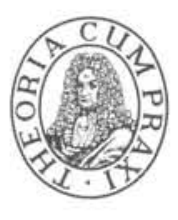

Akademie Verlag 
Bibliografische Information der Deutschen Nationalbibliothek Die Deutsche Nationalbibliothek verzeichnet diese Publikation in der Deutschen Nationalbibliografie; detaillierte bibliografische Daten sind im Internet über http://dnb.d-nb.de abrufbar.

ISBN 978-3-05-004531-3

(C) Akademie Verlag GmbH, Berlin 2010

Das eingesetzte Papier ist alterungsbeständig nach DIN/ISO 9706.

Alle Rechte, insbesondere die der Übersetzung in andere Sprachen, vorbehalten. Kein Teil dieses Buches darf ohne schriftliche Genehmigung des Verlages in irgendeiner Form - durch Photokopie, Mikroverfilmung oder irgendein anderes Verfahren - reproduziert oder in eine von Maschinen, insbesondere von Datenverarbeitungsmaschinen, verwendbare Sprache übertragen oder übersetzt werden.

Satz: HSB Telecom \& Multimedia, Altenmünster

Druck und Bindung: Druckhaus „Thomas Müntzer“ GmbH, Bad Langensalza

Printed in the Federal Republic of Germany 
MEINEM VEREHRTEN FREUND

\section{ETIENNE LAMOTTE}

\section{GEWIDMET}


